\title{
SOLID WOOD SURFACE MODIFICATION BY CHARRING AND ITS IMPACT ON REACTION TO FIRE PERFORMANCE
}

\author{
Edgars Buksans $^{1}$, Laura Laiveniece ${ }^{1}$, Valters Lubinskis ${ }^{2}$ \\ ${ }^{1}$ Forest and Wood Products Research and Development Institute, Latvia; \\ ${ }^{2}$ Pavasars wood constructions Ltd, Latvia \\ edgars.buksans@e-koks.lv.lv, laura.laiveniece@e-koks.lv,valterslubinskis@gmail.com
}

\begin{abstract}
Wood surface modification by charring is known for centuries, as Japanese craftsmen used this wood protection method for wood usage in outdoor exposure. This technology is well known as Shou sugi ban or Yakisugi and this treatment creates a thick char layer on the wood element surface, which later protects wood from biological attack for decades. Nowadays, it has become also a popular wood treatment method in the EU countries, mainly for decorative purposes. Wood surface modification by charring followed by brushing creates decorative looking wood surface with nice dark texture of latewood and light earlywood. The aim of this research was to develop a technology for decorative wood surface modification by the charring method and evaluate its impact on reaction to fire performance. Reaction to fire performance of modified wood prototypes was tested by the cone calorimeter method as a small-scale test and a single burning item (SBI) was used for large scale testing, which allows to determine the reaction to fire class according to the EU official classification system according to EN 13501-1:2018. It was found that wood surface modification improves reaction to fire performance of modified wood, when the char layer remains as facing, but decreased fire performance was observed, when the char layer removed by brushing. Additional fire retardant treatment application on modified wood surface was investigated to evaluate potential of reaction to fire class improvement. However, it is more difficult to improve reaction to fire performance of modified wood with charred surface compared to untreated wood.
\end{abstract}

Keywords: charring, wood modification, reaction to fire, fire protection.

\section{Introduction}

Wood various chemical, thermal, surface or impregnation treatment modification methods are increasingly popular approaches to improving wood properties. Thermal modification is one of the most commercialized methods to advance such wood properties as dimensional stability, surface hardness, water, biological and weather resistance, colour change, durability and sustainability [1-5].

Thermal modification is controlled pyrolysis of wood being treated at high temperatures depending on the wood species between $160{ }^{\circ} \mathrm{C}$ and $260^{\circ} \mathrm{C}$ for several hours at steam, nitrogen atmosphere or using hot oil, etc. to avoid burning [3-8]. During the thermal modification occurs decomposition and destruction of the thermally unstable and least resistant wood components, for example, polysaccharides and extractive components and chemical structures of cell wall components (lignin, cellulose and hemicelluloses) are modified [6-7]. Thereby increases not only the wood's resistance to biological degradation and weather exposure, water uptake, cracking tendency and its aesthetic value, but also fire characteristics improve, such as lower smoke release rate, lower value of the heat release rate peak at the moment of ignition and lower weight loss [3-4; 7-8].

Wood charring is an old Japanese technique called Shou sugi ban or Yakisugi, which is used to increase the wood durability and sustainability [5;9]. Due to its aesthetically and natural look nowadays there are several companies producing charred wood also in Europe and in the USA. During the charring process as a type of thermal modification pyrolysis occurs, in which most reactive components of wood are degraded, thereby decreases water uptake and both the mechanical and the biological durability should increase [9]. However, compared to thermal modification wood surface charring modifies only the exposed surface, saves time and costs, as well as maintains mechanical properties of wood [5]. Although there are scientific studies about moisture uptake, weathering durability and sustainability about charred wood, still research about such important property as fire performance of charred wood is missing.

The cone calorimeter is a small-scale fire testing device, which is widely used to determine fire performance properties of materials and products. However, cone calorimeter is the only method for product screening and control, but none of the test methods of the EU official classification system according to the standard EN 13501-1:2018 is used to determine reaction to fire class [10]. Large scale single burning item test (SBI), which is one of the official classification methods, is used for testing and determining reaction to fire class of materials. Both test methods are based on the same principles for 
measurement of fire performance parameters, such as heat release and smoke production rate. There exist models, which are able to predict reaction to fire class from cone calorimeter results with relatively high accuracy [11-12].

The aim of this research was to develop a technology for decorative wood surface modification by the charring method and evaluate its impact on reaction to fire performance.

\section{Materials and methods}

Experimental work started with development of the wood surface charring technology. The main physical factor of the surface of charred wood is the char thickness. Hypothetically the charr layer thickness is one on the most important factors, which influence reaction to fire performance of the product in end use. First experiments were done at fixed heat flux in radiant panel equipment, where uniform distribution of heat flux on the surface of wood specimen was created. Flooring radiant panel for fire testing according to EN ISO 9239-1:2010 was used as a heat source and special specimen holder was made to create even heat distribution, see Fig. 1 [13]. Specimens were arranged parallel to the burner with $40 \mathrm{~mm}$ distance.

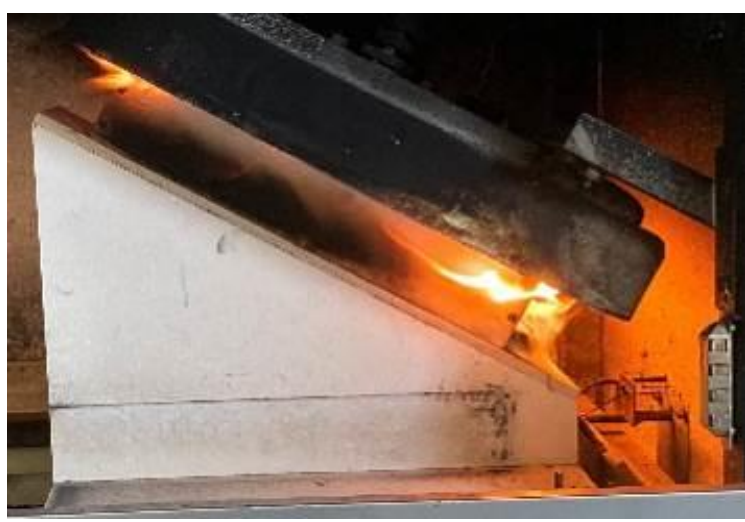

1.

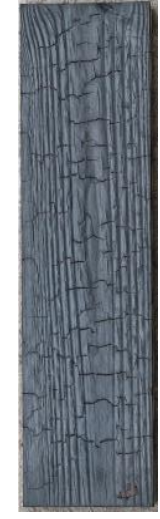

2.

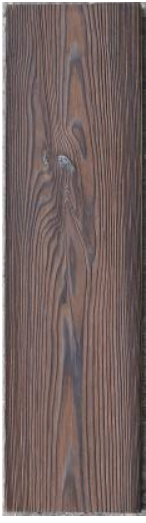

3.

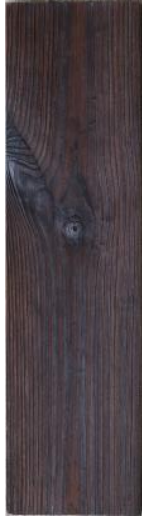

4.

Fig. 1. Charring process at flooring radiant panel: 1 - equipment; 2 - charred wood sample; 3 - brushed sample after charring; 4 - brushed sample with oil coating

Five different exposure times were used to find optimal charring quality: $90 \mathrm{~s} ; 105 \mathrm{~s} ; 120 \mathrm{~s} ; 135 \mathrm{~s}$; $150 \mathrm{~s}$, which made charr depth from $0.6 \mathrm{~mm}$ to $2.6 \mathrm{~mm}$. Optimal charring depth $1.5 \mathrm{~mm}$ was chosen as a result of visual evaluation of the charred surface quality. This charring depth was achieved at $120 \mathrm{~s}$ fire exposure time.

Pine (Pinus Sylvestris L.) and spruce (Picea Abies) wood species were used for charred surface experiments, which are most suitable wood species in the Baltic and Nordic region to create durable and visually outstanding texture of cladding boards. Different mechanical properties of earlywood and latewood give a possibility to highlight the wood texture by brushing of charred wood, see Fig. 1. Both cladding variations charred only and brushed are being used in building elements. The idea to use fire retardant chemical for wood surface treatment before the charring process also was investigated with the aim to improve the charr layer quality and improve fire performance of charred wood products.

Experimental equipment for charred wood manufacturing was designed and built for large scale experiments. Heat exposure to the specimen surface was applied by propane burners, which were designed perpendicularly to the board surface and to be adjustable in height. In total eight burners were used to expose boards from all four sides. Equipment model prototype is shown in Fig. 2. Adjustable continuous flow of wood materials through the gas burner zone allowed to set up the necessary fire exposure time to create the charr layer thickness about $1.5 \mathrm{~mm}$. More detailed setup of equipment is not presented in this paper to keep intellectual property of the developer.

Reaction to fire performance of charred pine wood was determined by small scale fire test method - cone calorimeter according to ISO 5660-1:2015 test method [14]. These specimens were prepared in laboratory on flooring radiant panel equipment by using wood samples with dimensions $375 \times 100 \times 20 \mathrm{~mm}$. Totally 36 boards were treated by fire exposure and half of them were brushed after charring for each fire exposure. One most appropriate surface treatment with linseed oil was applied on 
charred specimens and brushed as well. Three specimens of each product variation were tested at cone calorimeter test.
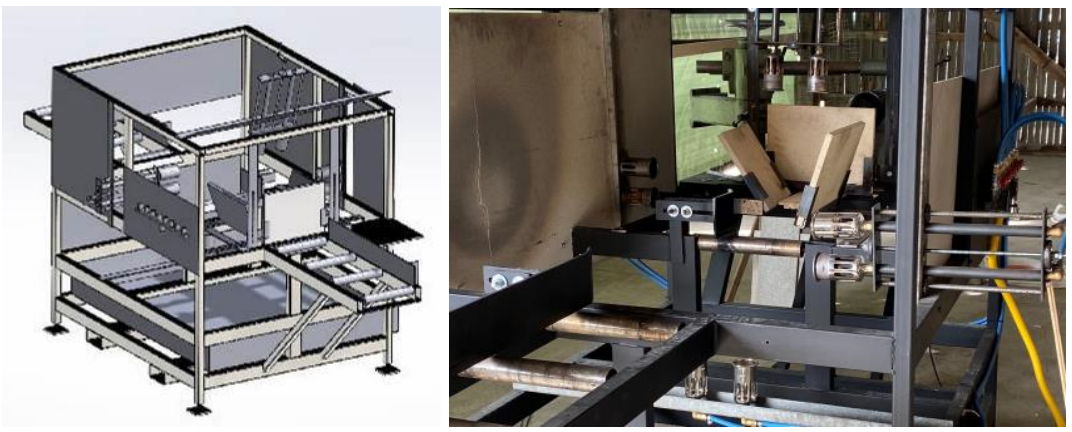

Fig. 2. Charring equipment model and burner setup in real prototype

Large scale technology validation was done with spruce wood species on the experimental charring equipment. Boards with dimensions $32 \times 105 \times 4800 \mathrm{~mm}$ were used and $24 \mathrm{~m}^{2}$ of product were prepared for large scale testing at single burning item test according to EN 13823:2010. Half of charred boards were brushed at an industrial brushing machine. Three specimens of charred surface and brushed surface were prepared and tested according to the EN 13823:2010 test method [15].

Improvement of charred wood fire performance by fire retardants was done only for charred surface boards. Three random fire retardants from market ensuring B-s1, d0 reaction to fire class for solid wood materials were selected and one specimen per each fire retardant was made for large scale test according to EN 13823:2010. Fire retardants were identified by FR1; FR2 and FR3 and treatment was done by brushing with one single layer with consumption $200 \mathrm{~g} \cdot \mathrm{m}^{-2}$. All fire tests were performed only after the conditioning process completed according to EN 13238:2010 [16]. Conditioning parameters were $23^{\circ} \mathrm{C}$ temperature and $50 \%$ relative humidity, which brings normal wood products to moisture content $9-10 \%$. Results were compared to reference unmodified pine and thermally modified pine wood reaction to fire performance, which were described in Bukšāns (2010) PhD thesis [17].

\section{Results and discussion}

Reaction to fire performance is one of the most important properties of construction products. As growing popularity of charred surface wood products now can be observed in market, the properties of this modified wood product are becoming more and more actual. Two wood species were used in this research work. First stage - laboratory scale experiments were done with pine wood. Cone calorimeter testing of all product variations according to ISO 5660-1:2015 standard was done [14]. Specimens1) charred wood; 2) brushed after charring; 3 ) charred with linseed oil top coating; 4) brushed with linseed oil treatment; 5) fire retardant treated and charred; 6) fire retardant treated and brushed after charring, were tested and the results were compared to single unmodified pine wood and thermally modified pine wood at temperature $195^{\circ} \mathrm{C}$. Specimen before, during and after the test is shown in Fig.3. This example is for charred and brushed wood, where deep texture of wood opened by the removed softwood part can be observed.

William Beleck has published the article "The science behind flame retardancy of Shou Sugi Ban/Yakisugi" at global network and it is the only exiting description of fire properties of charred wood [18]. He described results achieved by ASTM standards UL classes, which cannot be compared to the European fire classification system, and the question about fire performance changes as the charring process remains open. The wood surface charring process starts from heating up the top layer of wood, where the first pyrolysis processes start at the temperature above $140{ }^{\circ} \mathrm{C}$ [17]. In deep discussion of this question, it is important to split this product in a three-layer product consisting of different materials, which are created in the wood pyrolysis process. The first is normal wood, without any damage and fire properties of this part should remain unchanged. The second layer is a thermally modified wood layer, which has decreased equilibrium moisture content and has better biological stability, but fire properties should be worse than for unmodified wood. The third layer is deep charr, which is very resistant in biological durability and works as a good insulation material preventing wood from a fast pyrolysis process. Charr oxidation can occur only by glowing combustion, where no flames can be observed on 
the wood surface. And this becomes the main reason of opinions about fire resistance of charred wood like Shou Sugi Ban.

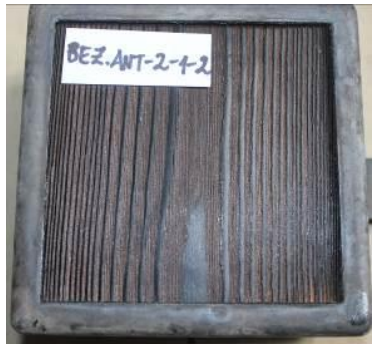

1.

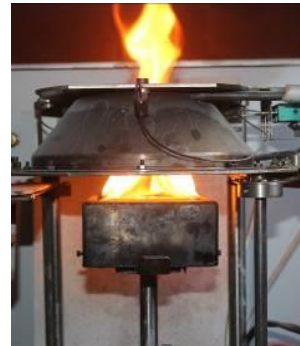

2.

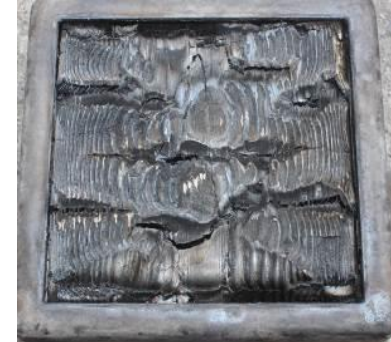

3.

Fig. 3. Cone calorimeter test ISO 5660-1: 1 - specimen before test;

2 - test; 3 - specimen after test

The experimental data obtained at cone calorimeter test for all product groups are shown in Fig. 4. Peak heat release rate (HRRmax) is one of the most important factors for reaction to fire performance prediction in single burning item [19]. Second important factor to compare is maximal average rate of heat emission (MARHE). Both are measured at $\mathrm{kW} \cdot \mathrm{m}^{-2}$ units. The charring process decreased HRR max 1.9 times, which potentially predicts $C$ class performance according to EN 13501-1:2018 for this product variation. It cannot be observed that fire retardant treatment of wood before charring gives additional benefits to reaction to fire performance.

Brushing process removes the soft layer of charr and the very thin layer of modified latewood remains on the surface. This product now mainly consists of thermally modified wood and untouched wood. In fire tests it can be observed that HRR max decrease is by $45 \%$ and it is only $4 \%$ less than for untreated wood. MARHE becomes close to unmodified pine wood. Fire performance of the thermally modified wood (Thermo Pine) was slightly worse than charred-brushed wood but no more than $10 \%$ difference.

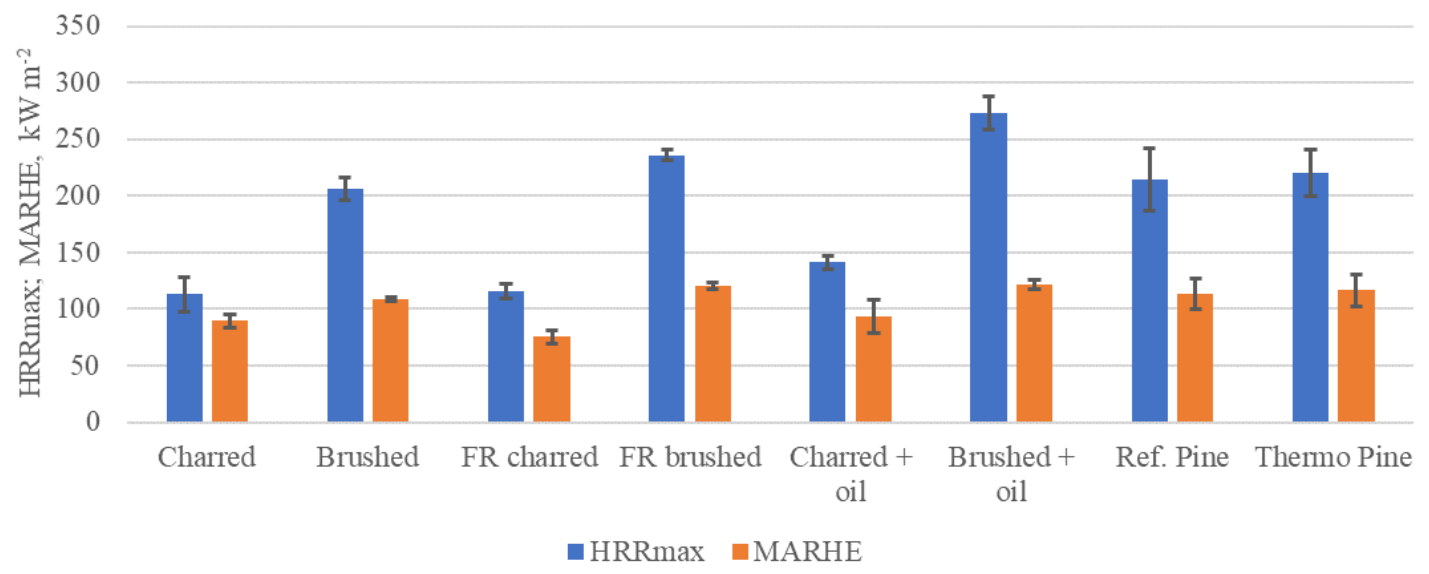

Fig. 4. Cone calorimeter test results - peak heat release rate (HRRmax) and maximal average rate of heat emission (MARHE)

Statistically all types of specimens showed good repeatability and error bars, in figures is shown standard deviation of the achieved results, which was achieved by 3 replicants. Significant increase by $32 \%$ in HRRmax factor was observed for brushed specimens, which were treated with linseed oil. Addition coatings need to be used in the end use to protect wood products from weather moisture attacks, but from the point of fire performance view, additional coatings will reduce fire properties of wood products and can be the reason to change reaction to fire classification.

The scale of fire tests always plays a significant role on fire performance of construction products. Full scale fire experiments are too expensive and dangerous, that is why smaller and more controlled methods are used in evaluation of fire performance of building materials. One medium scale test method 
used in the official classification system in Europe is single burning item test (EN 13823:2010), which was used for second stage experiments for charred wood fire performance evaluation.

Spruce wood material was available for factory scale validation experiment and boards with $4.5 \mathrm{~m}$ length were prepared in the charring machine. Five types of products were prepared: 1) charred wood; 2) charred and brushed wood; 3) 3 different fire retardants applied on charred wood to check the possibility to improve fire performance of charred wood products. All the results were compared to untreated reference spruce wood performance. All the variations have 3 replicants except fire retardant treated variations. The results are summarized in Fig. 5 and 6, and specimens after tests are shown in Fig.7.

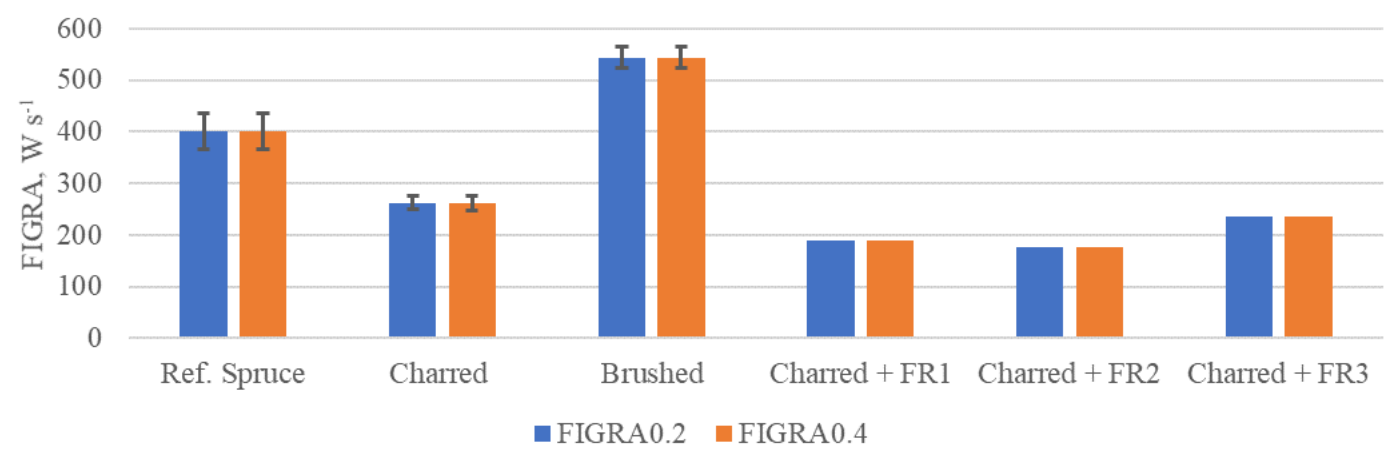

Fig. 5. SBI test results - fire growth rate index (FIGRA)

Fire growth rate index FIGRA0.2 is used for classification of products in B class, but FIGRA0.4 in $\mathrm{C}$ and $\mathrm{D}$ classes. For all specimens these indexes were identical or very close due to continuously growing heat release rate phenomena. Only SBI test results are giving real fire performance evaluation for classification purposes and it was observed that the charring process decreased FIGRA0.4 by 35\%, but it was not enough to classify them in better reaction to fire class C, where FIGRA0.4 threshold value is $250 \mathrm{~W} \cdot \mathrm{s}^{-1}$. FIGRA0.4 for charred wood in average was $262.9 \mathrm{~W} \cdot \mathrm{s}^{-1}$, which was very close to C class. Increased charr layer thickness or usage of special surface treatment chemicals can give a possibility to this material achieve $\mathrm{C}$ or even $\mathrm{B}$ class fire performance. This hypothesis was proved by usage of three different fire retardants after charring. All three of them give potential fire performance in C-s $2, \mathrm{~d} 0$ class. Classification to C class performance uses also the total heat release factor in the first $600 \mathrm{~s}$ (THR600s), which also was evaluated in Fig. 6. Brushing after charring increased FIGRA0.4 more than two times, but the product remained in euroclass $\mathrm{D}$, while it is also 35\% higher FIGRA0.4 than untreated reference spruce wood.

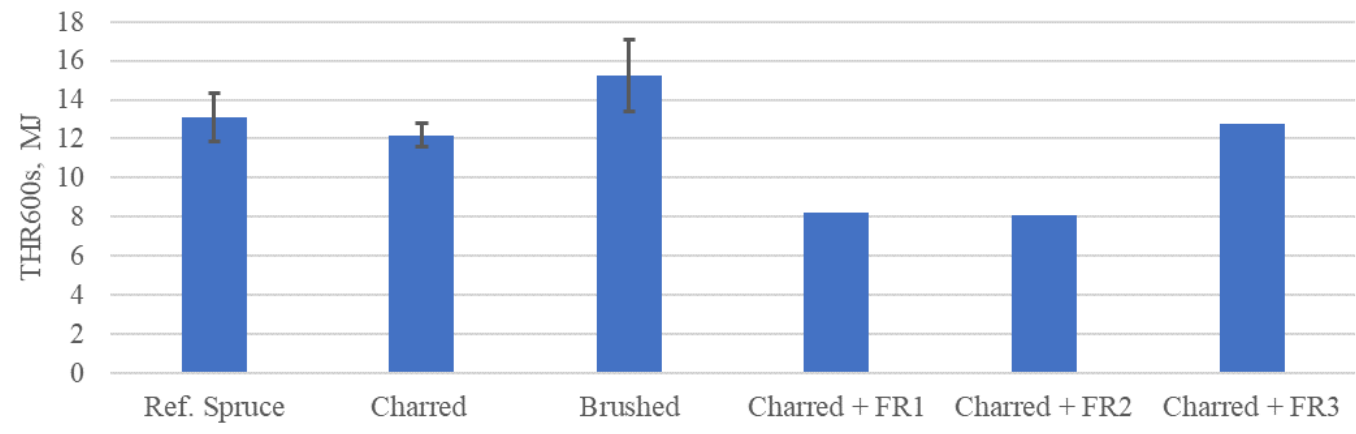

Fig. 6. SBI test results - total heat release rate in $600 \mathrm{~s}$ (THR600s)

Additional observations were related with the smoke development factor - total smoke production in $600 \mathrm{~s}$ (TSP600s), which increased for all charred wood variations by 2.5 to 3 times. And the smoke index according to classification rules of EN 13501-1 decreased from s1 to s2. Reaction to fire class of charred wood products can be easily improved by fire retardant chemicals, but only those which maks fixation in the char layer should be used to avoid leaching in the product end use. 


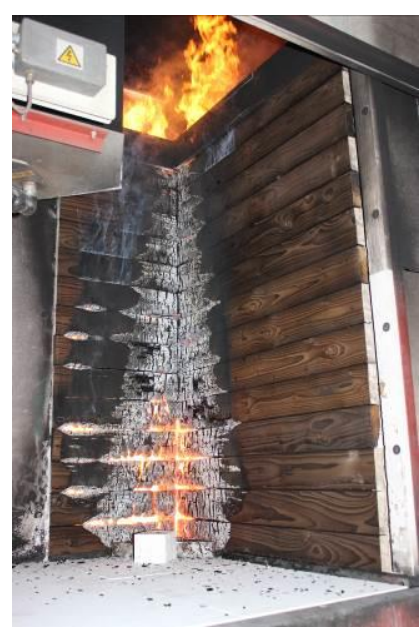

1.

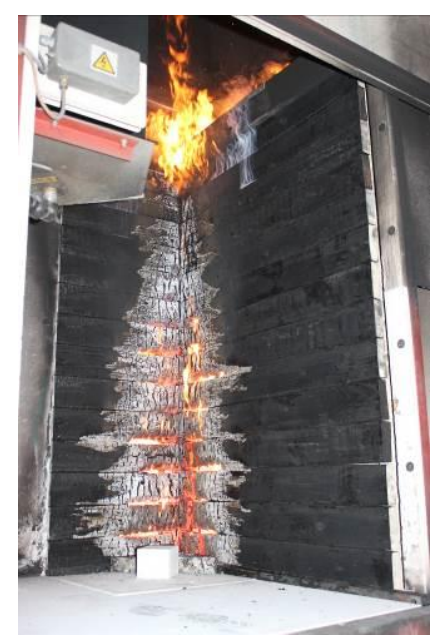

2.

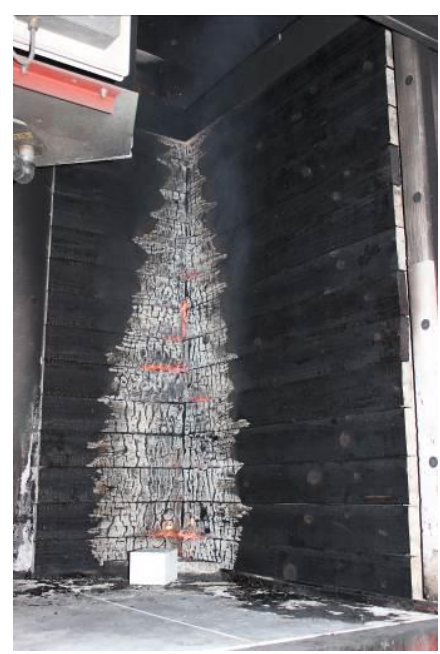

3.

Fig. 6. Specimens after SBI tests: 1 - brushed; 2 - charred; 3 - charred with fire retardant treatment.

\section{Conclusions}

1. Improvement of reaction to fire performance of charred surface wood products can be achieved only by the remaining all solid char layer on the wood product and an additional charr fixation coating is preferable to ensure long lasting durability.

2. Brushing after charring gives wood products outstanding texture, but decreases fire performance to levels below untreated wood.

3. Charred wood products have significantly higher smoke developments, which is going to change reaction to the fire smoke index classification.

\section{Acknowledgements}

In accordance with the contract No. 1.2.1.1/18/A/004 between "Forest Sector Competence Centre of Latvia" Ltd. and the Central Finance and Contracting Agency, concluded on 17th of April, 2019, the study is conducted by "Forest and Wood Products Research and Development Institute" Ltd. and "Pavasars wood constructions" Ltd with support from the European Regional Development Fund (ERDF) within the framework of the project "Forest Sector Competence Centre".

\section{References}

[1] Žlahtič M., Humar M. Influence of Artificial and Natural Weathering on the Moisture Dynamic of Wood. BioResources, vol. 12(1), 2017, pp. 117-142.

[2] Luptáková J., Kačik F., Mitterová I. etc. Influence of Temperature of Thermal Modification on the Fire-technical Characteristics of Spruce Wood. BioResources, vol. 14(2), 2019, pp. 3795-3807.

[3] Čekovská H., Gaff M., Osvald A. etc. Fire Resistance of Thermally Modified Spruce Wood. BioResources, vol. 12(1), 2017, pp.947-959.

[4] Jirouš-Rajković V., Miklečić J. Weathering Resistance of Modified Wood - A Review. Jubilee annual 2017-2018 of the Croatian Academy of Engineering, 2018, pp. 223-246.

[5] Čermák P., Dejmal A., Paschová Z. etc. One-sided surface charring of beech wood. Journal of Materials Science, vol. 54, 2019, 9497-9506.

[6] Homan W.J., Jorissen A.J.M. Wood modification developments. HERON, vol. 49, 2004, pp. 361386.

[7] Martinka J., Chrebet T., Král J. etc. An examination of the behaviour of thermally treated spruce wood under fire conditions. Wood Research, vol. 58(4), 2013, pp. 599-606.

[8] Candelier K., Thevenon M.F., Petrissans A. etc. Control of wood thermal treatment and its effects on decay resistance: a review. Annals of Forest Science, vol. 73, 2016, pp. 571-583.

[9] Kymäläinen M., Hautamäki S., Lillqvist K. etc. Surface modification of solid wood by charring. Journal of Materials Science, vol. 52, 2017, pp. 6111-6119. 
[10] EN 13501-1:2018 standard "Fire classification of construction products and building elements Part 1: Classification using data from reaction to fire tests". CEN/TC 127 Fire safety in buildings.

[11] Lindholm J., Brink A., Hupa M. Cone calorimeter - a tool for measuring heat release rate. [online] [15.03.2021.]. Available at: https://www.researchgate.net/publication/242266790_CONE_CALORIMETER__A_TOOL_FOR_MEASURING_HEAT_RELEASE_RATE

[12] Hansen A.S. Prediction of Heat Release in the Single Burning Item Test. Fire and Materials, vol. 26, 2002, pp. 87-97.

[13]EN ISO 9239-1:2010 standard "Reaction to fire tests for floorings - Part 1: Determination of the burning behaviour using a radiant heat source". CEN/TC 127 Fire safety in buildings.

[14] ISO 5660-1:2015 standard "Reaction-to-fire tests Heat release, smoke production and mass loss rate". ISO/TC 92/SC 1 Fire initiation and growth.

[15] EN 13823:2010 standard "Reaction to fire tests for building products - Building products excluding floorings exposed to the thermal attack by a single burning item". CEN/TC 127 Fire safety in buildings.

[16]EN 13238:2010 standard "Reaction to fire tests for building products - Conditioning procedures and general rules for selection of substrates". CEN/TC 127 Fire safety in buildings.

[17] Bukšāns E., (2010) Different factor influence on fire safety of wood materials and prediction of the reaction to fire. $\mathrm{PhD}$ Thesis, Latvia University of Agriculture. $127 \mathrm{pp}$.

[18] Beleck W. The Science Behind Flame Retardancy of Shou Sugi Ban/Yakisugi. [online] [15.03.2021]. Available at: https://nakamotoforestry.com/the-science-behind-flame-retardancy-ofshou-sugi-ban-yakisugi/

[19] Hees P.V., Hertzberg T., Hansen A.S. Development of a Screening Method for the SBI and Room Corner using Cone Calorimeter. [online] [15.03.2021]. Available at:

https://www.researchgate.net/publication/266389757_Development_of_a_screening_method_for_ the_SBI_and_Room_Corner_Test_based_on_the_Cone_Calorimeter 